\title{
Analysis and Comparison of Carbon Emissions of Different Asphalt Mixing Process
}

\author{
CAO Yi ${ }^{1, a}$, HUANG Xiaoming ${ }^{1, b}$, DING Jing ${ }^{1, c}$ \\ ${ }^{1}$ School of Transportation Southeast University, China \\ a email: \\ caoyi2378@126.com, bemail:huangxm@seu.edu.cn,cemail:244092869@ \\ qq.com
}

\begin{abstract}
.
The thesis firstly defines the studying types of greenhouse gases. Then according to calculation method, we get the carbon emissions of common energies as calculation base. The thesis uses thermodynamic method to calculate the diesel consumption of HMA and WMA and gets the electricity cost according to literature, at last we use quota method to calculate the carbon emission. For asphalt recycling, we consider the total process including material production, transportation and mixing and calculate the carbon emissions with different RAP ratios. In conclusion, the WMA and recycling with certain RAP ratio reduce emission

. Keywords: Mixing Process; Carbon Emissions; Warm Mixing Asphalt; Asphalt Recycling
\end{abstract}

\section{Introduction}

As global warming is progressively influencing our daily life, the topic of greenhouse gas emissions has been increasingly focused and discussed in many study fields, particularly the application of various effective measures on energy saving and emission reduction. In pavement engineering, hot mixture asphalt(HMA) technology is a conventional mixing process to produce asphalt mixture. However, HMA technology will consume a relatively high amount of electricity and diesel energy, which will lead to massive carbon emissions ${ }^{[1-2]}$. Warm mixture asphalt (WMA) technology refers to a mixing process during which the mixing temperature is between hot mixture asphalt and cold mixture asphalt technology. This WMA technology of decreasing the mixing temperature will effectively save the energy and therefore reduce the carbon emissions, but there has not been a quantitative calculating method to obtain the practical savings of WMA. Therefore, this thesis proposes a feasible quantitative calculating method to compare the carbon emissions of HMA and WMA technology. In addition, asphalt regeneration process is also discussed to study the quantitative carbon emissions calculation. Asphalt regeneration process mainly divides into recycling in plant and recycling in place, among which recycling in plant is 
generally used. Asphalt regeneration recycles the old material, which will save the corresponding energy in producing raw material ${ }^{[3]}$. However, the use of regeneration technology in mixing process may consume much more energy, so a comprehensive quantitative study of carbon emissions in regeneration and conventional mixing process is extremely needed.

\section{Calculation Method of Carbon Emissions}

Carbon Equivalent Formula. The carbon dioxide equivalence computation, which is used to compare the carbon emissions of different mixing process, adopts GWP(Global Warming Potential) to convert other gas quality into carbon dioxide equivalence considering the environmental influence of a particular gas in a period of 100 years(or other time period), and then sum the emissions of various greenhouse gases $^{[4]}$. The equation is as follows:

$$
m C O_{2 e q}=\sum G W P_{i} \times m_{i}
$$

Where mCO2eq is the total equivalence of carbon dioxide; GWPi is the global warming potential of type i gas; mi is the gas quality of type $i$.

This greenhouse gases used in this paper include $\mathrm{CO}_{2}, \mathrm{CH}_{4}$ and $\mathrm{N}_{2} \mathrm{O}$ stipulated in Kyoto Protocol. The 100 year GWP is 1, 27 and 310 respectively according to previous study.

Carbon Emissions Calculation of Common Energy. The general carbon emissions calculation of energy mainly considers the burning and producing process, while secondary energy such as electricity merely consider its producing process. The carbon emissions calculation of common energy is computed as Table 1, which is based on Chinese Life Cycle Database and previous study in carbon emissions of energy.

Table1 Carbon emissions calculation of common energy

\begin{tabular}{ccccc}
\hline Energy[kg, kwh] & $\mathrm{CO}_{2}[\mathrm{~kg}]$ & $\mathrm{CH}_{4}[\mathrm{~kg}]$ & $\mathrm{N}_{2} \mathrm{O}[\mathrm{kg}]$ & $\begin{array}{c}\mathrm{CO}_{2} \\
\text { equivalence[kg } \\
]\end{array}$ \\
\hline $\begin{array}{c}\text { Raw coal } \\
\text { Diesel oil(moving } \\
\text { source) }\end{array}$ & 3.4568 & $3.8643 \times 10^{-4}$ & $1.7512 \times 10^{-4}$ & 3.5215 \\
$\begin{array}{c}\text { Diesel } \\
\text { oil(stationary } \\
\text { source) }\end{array}$ & 3.4568 & $3.4714 \times 10^{-4}$ & $2.9999 \times 10^{-5}$ & 3.4755 \\
$\begin{array}{c}\text { Electricity } \\
\text { Gasoline }\end{array}$ & 0.762 & $2.3 \times 10^{-3}$ & $1.42 \times 10^{-5}$ & 0.8285 \\
\hline
\end{tabular}




\section{The Carbon Emissions Comparison of HMA and WMA Technology}

Thermodynamic Equation. The equation of thermodynamic method is as follows:

$$
\begin{aligned}
& E=c m \Delta t \\
& E=L_{V} \Delta m
\end{aligned}
$$

where $\mathrm{E}$ is the energy consumption, $\mathrm{J}$; $\mathrm{C}$ is the specific heat, $\mathrm{J} /\left(\mathrm{kg}{ }^{\circ} \mathrm{C}\right) ; \mathrm{m}$ is the quality, $\mathrm{kg}$; is the change of temperature, ${ }^{\circ} \mathrm{C}$; $\mathrm{Lv}$ is the latent heat, $\mathrm{kJ} / \mathrm{kg}$, is the change of quality, kg.

From which, equation(2) is applied for normal heating process, and equation(3) is applied for liquid evaporating process.

Calculating Parameter and Energy Consumption. The heating process being considered includes the heating of aggregate, water evaporation (two aspects, the heat for evaporation and taken away by vapor), and the heating of asphalt ${ }^{[3]}$. The heating temperature of HMA and WMA in different process is as Table3:

Table3. Aggregate and Asphalt Heating Temperature of HMA and WMA

Technology

\begin{tabular}{ccccc}
\hline $\begin{array}{c}\text { Type of } \\
\text { mixture }\end{array}$ & $\begin{array}{c}\text { The initial } \\
\text { heating } \\
\text { temperature of } \\
\text { aggregate }\left[{ }^{\circ} \mathrm{C}\right]\end{array}$ & $\begin{array}{c}\text { The final } \\
\text { heating } \\
\text { temperature of } \\
\text { aggregate }\left[{ }^{\circ} \mathrm{C}\right]\end{array}$ & $\begin{array}{c}\text { The initial } \\
\text { heating } \\
\text { temperature of } \\
\text { asphalt }\left[{ }^{\circ} \mathrm{C}\right]\end{array}$ & $\begin{array}{c}\text { The final } \\
\text { heating } \\
\text { temperature of } \\
\text { asphalt }\left[{ }^{\circ} \mathrm{C}\right]\end{array}$ \\
\hline HMA & 25 & 180 & 130 & 170 \\
WMA & 25 & 140 & 130 \\
\hline Table4. Calculating Parameter of HMA and WMA Technology
\end{tabular}


The grain type asphalt concrete is used in mixing process, the aggregate-asphalt ratio of which is $4.8 \%$. Other calculating parameters are shown in Table4. After converting the energy consumption of three processes into diesel consumption, the diesel consumption in heating process of HMA and WMA technology is shown as Table5.

Table5. Diesel Consumption in Heating Process of HMA and WMA Technology

\begin{tabular}{ccccc}
\hline & \multicolumn{2}{c}{ Energy needed in heating process[J] } & & $\begin{array}{c}\text { Total diesel } \\
\text { Type }\end{array}$ \\
\cline { 2 - 3 } & Asphalt & Aggregate & $\begin{array}{c}\text { Water heating and } \\
\text { evaporating }\end{array}$ & \\
HMA & $2.5728 \times 10^{6}$ & $1.3576 \times 10^{8}$ & $4.8952 \times 10^{7}$ & 6.755 \\
WMA & 0 & $1.0072 \times 10^{8}$ & $4.8952 \times 10^{7}$ & 5.399 \\
\hline
\end{tabular}

Table5 shows that the total diesel consumption in HMA is $6.755 \mathrm{~kg}$, while in WMA is $5.399 \mathrm{~kg}$, which indicates that WMA technology saves $20.0 \%$ diesel consumption compared to HMA technology.

In addition, the electricity consumed in mixing process of HMA and WMA is similar because of the same electrical equipment used. The electricity consumption of different electrical equipment can be inquired as follows: LB2000

$(160 \mathrm{t} / \mathrm{h})$ is $3.19 \mathrm{kwh} / \mathrm{t}, \mathrm{LB} 3000(240 \mathrm{t} / \mathrm{h})$ is $2.85 \mathrm{kwh} / \mathrm{t}, \mathrm{LB} 4000(320 \mathrm{t} / \mathrm{h})$ is $2.70 \mathrm{kwh} / \mathrm{t}^{[5]}$. The electricity consumption value used in this study is $2.70 \mathrm{kwh} / \mathrm{t}$ from LB4000 (320t/h).

Carbon Emissions in Basic Unit. The 1000m3 grain type asphalt concrete is used as the basic unit in this paper, the density of which is $2.358 \mathrm{t} / \mathrm{m} 3$. In order to calculate the carbon emissions in basic unit of HMA and WMA technology, diesel emission consumed by loading machine is also taken into consideration except for fuel consumption and electricity consumption discussed above. Based on the Budgetary Norm of Highway Project and Machinery Team expense Quota of Highway Engineering, it can be inquired that the $1000 \mathrm{~m}^{3}$ grain type asphalt concrete of 320t/h equipment consumes 2.53 machine-teams of loading machine within $3 \mathrm{~m}^{3}$, and the diesel consumption rate is $115.15 \mathrm{~kg}$ per machine-team. Therefore the diesel consumption in loading machine is $291.3295 \mathrm{~kg}$. Then the totalcarbon emissions can be computed using calculation method as previous studied. The carbon emissions comparison of HMA and WMA technology is shown in Table 6.

Table 6 The Comparison of Carbon Emissions in Basic Unit of HMA and WMA Technology

\begin{tabular}{|c|c|c|c|c|}
\hline Type & $\begin{array}{c}\text { Diesel consumption } \\
\text { (moving source) of loading } \\
\text { machine }[\mathrm{kg}]\end{array}$ & $\begin{array}{l}\text { Diesel consumption } \\
\text { (stationary source) of } \\
\text { mixing process[kg] }\end{array}$ & $\begin{array}{c}\text { Electricity } \\
\text { consumption of } \\
\text { electrical } \\
\text { equipment[kwh] }\end{array}$ & $\begin{array}{c}\text { Carbon } \\
\text { dioxide } \\
\text { equivalence } \\
{[\mathrm{kg}]}\end{array}$ \\
\hline
\end{tabular}




\begin{tabular}{ccccc}
\hline HM & 291.33 & 15928.76 & 6366.6 & 61660.42 \\
A & & 12730.22 & 6366.6 & 50544.00 \\
WM & 291.33 & 182 & \\
A & & & & \\
\hline
\end{tabular}

The results show that WMA reduces $18 \%$ carbon emissions in basic unit than HMA. Obviously, WMA technology can decrease the greenhouse gases to a large degree, and it is a effective measure for energy saving and emission reduction.

\section{Carbon Emissions Comparison of Recycling and Hot Mix Technology}

Environmental Load Unit. The productive processes of old material include milling of initial pavement, crushing and screening, during which carbon emissions are generated because of fuel and electricity consumption. It can be inquired that carbon emissions in old material generation are $4.28 \mathrm{~kg} / \mathrm{t}^{[6]}$, but the new material generation process involves many types of aggregate which is too complex to calculate. Therefore the productive emissions of metaling is adopted, and the value is $2.5 \mathrm{~kg} / \mathrm{t}$ from data source of Athena\&IVL. According to European Birch Bitumen Association, the emission value of asphalt is taken as $285 \mathrm{~kg} / \mathrm{t}$. The supply process also includes transportation of raw material, so the quota method is adopted to calculate the carbon emissions in this process. As previously discussed, the carbon emissions are calculated by diesel consumption resulted from the machine team of transport vehicles. In mixing process, carbon emissions of HMA technology is $26.26 \mathrm{~kg} / \mathrm{t}$, which is approximately the same with $26.2 \mathrm{~kg} / \mathrm{t}$ in literature, so the value from the literature can be adopted. However, when it comes to the mixing process of recycling asphalt mixture, the carbon emissions will augment due to the increasing temperature of new material and the supplement of new system. It can be inquired that the carbon emissions is $28.9 \mathrm{~kg} / \mathrm{t}$. The environmental load unit discussed above is shown as Table 7.

Table7. Environmental Load Unit

\begin{tabular}{ccc}
\hline Type & $\begin{array}{c}\text { Carbon dioxide equivalence } \\
(\mathrm{kg} / \mathrm{t})\end{array}$ & Data source \\
\hline Asphalt & 285 & Eurobitume \\
Aggregate (new material) & 2.5 & Athena\&IVL \\
RAP material & 4.28 & Literature[9] \\
$\begin{array}{c}\text { Mixing process of normal asphalt } \\
\text { mixture }\end{array}$ & 26.2 & \\
$\begin{array}{c}\text { Mixing process of recycling } \\
\text { asphalt mixture }\end{array}$ & 28.9 & \\
\hline
\end{tabular}

Carbon Emissions in Basic Unit. The $1000 \mathrm{~m}^{3}$ grain type asphalt concrete is used as the basic unit in this paper, the density of which is $2.358 \mathrm{t} / \mathrm{m}^{3}$, and the 
asphalt-aggregate ratio is $4.8 \%$. Suppose RAP material possesses the same asphalt content and density with new asphalt mixture. The distance of transport is assumed as follows: the average distance of asphalt from petroleum refinery to mix plant is $20 \mathrm{~km}$, the average distance of aggregate from quarry to mix plant is $15 \mathrm{~km}$, the average distance of old material from construction site to mix plant is $5 \mathrm{~km}$. The recycling asphalt mixture of $0 \%, 20 \%, 30 \%, 40 \%, 50 \%$ and $60 \%$ RAP ration are compared in this study to calculate content of asphalt, new material and old material, the material bill is shown in Table 8. Then the total carbon emissions in mixing process (including the supply of raw material) can be computed, and the results are shown in Table 9.

Table 8 Material Bill of Recycling Asphalt Mixture in Basic Unit

\begin{tabular}{ccccccc}
\hline RAP & $0 \%$ & $20 \%$ & $30 \%$ & $40 \%$ & $50 \%$ & $60 \%$ \\
\hline $\begin{array}{c}\text { Asphalt[t] } \\
\text { New } \\
\text { material[t] } \\
\begin{array}{c}\text { RAP } \\
\text { material[t] }\end{array}\end{array}$ & 113.465 & 90.772 & 79.426 & 68.079 & 56.733 & 45.386 \\
\hline
\end{tabular}

Table 9 Carbon Emissions Comparison in Basic Unit

\begin{tabular}{|c|c|c|c|c|c|c|}
\hline RAP ratio & $0 \%$ & $20 \%$ & $30 \%$ & $40 \%$ & $50 \%$ & $60 \%$ \\
\hline $\begin{array}{l}\text { Asphalt generation } \\
\text { ( kg) }\end{array}$ & 32337.53 & 25870.02 & 22636.27 & 19402.52 & 16168.76 & 12935.01 \\
\hline $\begin{array}{c}\text { New material } \\
\text { generation (kg) }\end{array}$ & 5611.34 & 4489.07 & 3927.94 & 3366.80 & 2805.67 & 2244.54 \\
\hline $\begin{array}{c}\text { RAP material } \\
\text { generation }(\mathrm{kg})\end{array}$ & 0 & 2018.45 & 3027.67 & 4036.90 & 5046.12 & 6055.34 \\
\hline $\begin{array}{l}\text { Transport of raw } \\
\text { material }(\mathrm{kg})\end{array}$ & 7110.32 & 6328.38 & 5937.40 & 5546.43 & 5155.45 & 4764.48 \\
\hline $\begin{array}{l}\text { Mixing of concrete } \\
\text { ( kg) }\end{array}$ & 61779.6 & 68146.2 & 68146.2 & 68146.2 & 68146.2 & 68146.2 \\
\hline Total（kg） & 106838.79 & 106852.11 & 103675.48 & 100498.84 & 97322.21 & 94145.57 \\
\hline
\end{tabular}

In order to intuitively exhibit carbon emissions and the variation trend of recycling asphalt mixture in different old material ratio, the diagram is made as shown 
1.

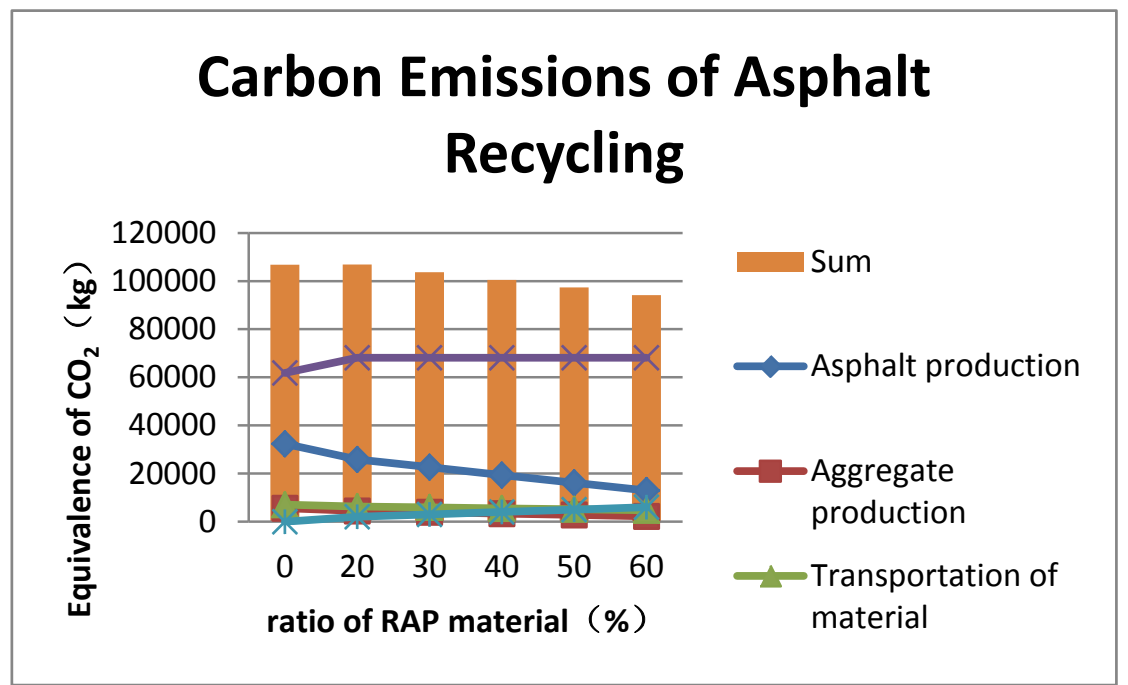

Figure 1. Carbon Emissions of Recycling Asphalt Mixture

The data shown in Table 8 indicates that the basic environmental load of old material is higher than new material, and similarly the basic environmental load of recycling asphalt mixture is higher than normal asphalt mixture. However, the calculation results in Table 10 show that when RAP ratio is up to 30\%,the carbon emissions of recycling mixture is lower than normal mixture, and the value decreases as the RAP ratio increases. The reason is exhibited in Figure 1, with the increasing ratio of RAP material, the asphalt and new material in raw material production is saved, which decreases the carbon emissions. And the use of old material make the starting points from quarry and petroleum refinery to construction plant, which decreases the transport distance and thus the carbon emissions in transport part decreases with the increasing RAP ratio. Also, the carbon emissions of RAP material productive and mixing process increase with the growing old material ratio, during this period the diminution exceeds the increment and the part in excess is increasing with the growing RAP ratio. Therefore, carbon emissions decrease with the growing ratio, but under relatively low RAP ratio $(10 \%, 20 \%)$, the emissions of recycling asphalt mixture can be higher than normal asphalt mixture.

\section{Conclusions}

(1)Compared with HMA technology, WMA technology can reduce $20.0 \%$ diesel consumption every ton, and decrease $18 \%$ final carbon emissions in mixing 1000m3grain type asphalt concrete.

(2)With the increasing RAP ratio, carbon emissions of recycling asphalt mixture decrease. Under relatively low RAP ratio(below 20\%), carbon emissions of recycling asphalt mixture is higher than HMA. And as RAP ratio up to a certain 
value, because the effect of material saving and transport distance reducing is significant, the carbon emission savings overweigh the increment generated by RAP productive and mixing process, the total carbon emissions of recycling asphalt mixture is lower than HMA, and the save is more obvious as RAP ratio increases.

In conclusion, WMA technology and recycling asphalt technology on certain old material ratio can save carbon emissions compared to HMA technology. They are effective measures of mixing process in energy saving and emission reducing and needed to be developed and adopted vigorously.

\section{References}

[1] Baorong Yuan, Zuoren Nie, Xianghua Di, et al. Life cycle inventories of fossil fuels in China( II ):Final life cycle inventories. Modern Chemical Industry, 2006,26(4): 59-61.

[2] Xiaolong Zou, Rong Li. Performance Study and Environmental Evaluation of Warm Mix Asphalt. Transportation Standardization, 2012 (13): 54-59.

[3] Harder G A, LeGoff Y, Loustau A, et al. Energy and environmental gains of warm and half-warm asphalt mix: quantitative approach[C]. Transportation research board 87th annual meeting. 2008 (08-2456).

[4] Xiaguang Hu, Fengzhen Wu, Feng Li, et al. Energy Conservation and Emission Reduction Technology in Road Construction and Maintenance. Journal of Xuzhou Institute of Technology(Natural Sciences Edition) , 2012, 27(1): 26-30.

[5] Nitta H, Nishizaki I. LCA Evaluation of Recycle Pavement Using Scrap Tire and Waste Plastic. Journal of Pavement Engineering, 2008: 79-86.

[6] Bilal J, Chappat M. The Environmental Road of the Future: Life Cycle Analysis, Energy Consumption and Greenhouse Gas Emissions. Colas Group, 2003. 